\title{
LAZER, VIRTUALIDADE E HOSPITALIDADE: \\ A PRÁTICA DO POKÉMON GO ENTRE ESTUDANTES UNIVERSITÁRIOS
}

\author{
LEISURE, VIRTUALITY AND HOSPITALITY: \\ THE POKÉMON GO PRACTICE AMONG UNIVERSITY STUDENTS
}

\author{
OCIO, VIRTUALIDAD Y HOSPITALIDAD: \\ LA PRÁCTICA DEL POKÉMON GO ENTRE ESTUDIANTES \\ UNIVERSITARIOS
}

\author{
Ricardo Ricci Uvinha ${ }^{1}$ \\ Giovanna Camargo Marttuci ${ }^{2}$ \\ Gustavo da Costa Bento ${ }^{3}$ \\ Melissa da Silva ${ }^{4}$
}

\section{Resumo:}

Buscou-se, no presente trabalho, a abordagem do jogo Pokémon GO como uma forma de lazer virtual, com enfoque na influência que este possui no cotidiano dos alunos da Universidade de São Paulo - USP. Foram analisados os motivos que tornam o ambiente universitário mais propício para a disseminação da prática de Pokémon GO, levando em consideração fatores como a segurança dentro do campus, a utilização do tempo livre dentro da universidade e a influência dos colegas universitários, entre outros. O procedimento metodológico adotado foi o tipo qualitativo, combinando enfoques bibliográfico e de campo. A pesquisa bibliográfica foi realizada em livros, dissertações e recentes artigos científicos publicados sobre a temática do Pokémon GO. Já a pesquisa de campo compreendeu um questionário aplicado com jogadores de Pokémon GO escolhidos aleatoriamente e compreendidos dentre um grupo de alunos da Escola de Artes, Ciências e Humanidades - EACH/USP. Os resultados apontam para a importância em estudar e compreender esse recente sucesso mundial em termos de impacto nas atividades de lazer de seus jogadores, além de analisar fatores que envolvem os universitários com o jogo e como a EACH/USP tornou-se, involuntariamente, hospedeira de alunos praticantes de Pokémon GO.

Palavras-chave: Pokémon GO. Lazer virtual. Entretenimento. Hospitalidade. Ambiente universitário.

\footnotetext{
Abstract:

This research study examined the game of Pokémon GO as a virtual leisure form and its influence University of Sao Paulo (USP) students and their daily routines. The reasons that made the university environment more propitious to the dissemination of Pokémon GO were analyzed, taking into account factors such as security within the campus, utilization of the free time within the university and the influence of their university peers, among others. A qualitative approach

${ }^{1}$ Professor Livre-docente do Programa de Pós-Graduação em Turismo da Universidade de São Paulo. Líder do Grupo Interdisciplinar de Estudos do Lazer GIEL/USP. Contato: uvinha@usp.br

${ }^{2}$ Graduanda em Lazer e Turismo da Universidade de São Paulo. Contato: giovanna.marttuci@usp.br

${ }^{3}$ Graduando em Lazer e Turismo da Universidade de São Paulo. Contato: gustavo.bento@usp.br

${ }^{4}$ Graduanda em Lazer e Turismo da Universidade de São Paulo. Contato: melissa2.silva@usp.br
} 
with bibliographical research in books, dissertations and recent scientific articles published about Pokémon GO, together with a field survey, were employed to examine this phenomenon. The field survey was carried out randomly on Pokémon GO players among students from the School of Arts, Sciences and Humanities, USP (EACH-USP). The results demonstrated the impact of Pokémon GO in the leisure activities of its players and factors that, unwittingly, made EACHUSP a conducive environment for Pokémon GO players.

Keywords: Pokémon GO. Virtual leisure. Entertainment. Hospitality. University environment.

\section{Resumen:}

El presente trabajo buscó el abordaje del juego Pokémon GO como una forma de ocio virtual, con enfoque en la influencia que este tiene en el cotidiano de los alumnos de la Universidade de São Paulo - USP. Fueron analizados los motivos que tornan el ambiente universitario más propicio para la diseminación de la práctica del Pokémon GO, llevando en consideración factores como la seguridad dentro del campus, la utilización del tiempo libre dentro de la universidad y la influencia de los colegas universitarios, entre otros. El procedimiento metodológico adoptado fue el tipo cualitativo, combinando enfoques bibliográficos y de campo. La pesquisa bibliográfica fue hecha en libros, disertaciones y recientes artículos científicos publicados sobre la temática del Pokémon GO. Ahora la pesquisa de campo comprende un cuestionario aplicado con jugadores de Pokémon GO, seleccionados de manera aleatoria dentro de un grupo de estudiantes de la Escola de Artes, Ciências e Humanidades - EACH/USP. El resultado apunta la importancia en estudiar y comprender ese reciente suceso mundial en termos de impacto en las actividades de ocio de sus jugadores, además analizar factores que envuelven los universitarios con lo juego y como la EACH/USP tornase, involuntariamente, hospedera de alumnos practicantes de Pokémon GO.

Palabras clave: Pokémon GO. Ocio virtual. Entretenimiento. Hospitalidad. Ambiente universitario.

\section{Introdução}

De propriedade da empresa japonesa de videogames Nintendo, a série Pokémon é considerada uma das principais franquias de mídia nos últimos tempos. Sua concepção remete a meados dos anos 1980 e tem, na figura de Satoshi Tajiri, seu principal idealizador. O nome Pokémon simboliza a união das palavras em língua inglesa Pocket e Monsters (Monstros de Bolso) correlatos ao início da franquia que foi lançada para o console portátil Game Boy da Nintendo.

Lançado inicialmente na Austrália, Estados Unidos e Nova Zelândia, o Pokémon GO se tornou um dos jogos mais praticados no mundo em apenas uma semana. Seu implacável sucesso trouxe fortes impactos para a Nintendo, já que tal empresa teve suas ações valorizadas em praticamente $100 \%$ num período de apenas sete dias ${ }^{5}$. Sugere-se assim que tal entretenimento tenha se tornado um hit, assim como muito bem descreve Trigo:

Há vários níveis de sucesso no universo do entretenimento. O mais elementar é o sucesso econômico, aquele produto que se paga e dá um lucro maior ou menor para todos os envolvidos em sua produção e distribuição. Um outro nível é o que se

\footnotetext{
${ }^{5}$ No Brasil, o Pokémon GO foi lançado em agosto de 2016 durante a ocorrência dos Jogos Olímpicos no Rio de Janeiro, megaevento esportivo que sabidamente trouxe ao Brasil um grande contingente de turistas estrangeiros.
} 
denomina hit (sucesso de grande impacto, em tradução livre). Ele proporciona um contexto cultural no qual as pessoas se identificam (TRIGO, 2003, p.165-166).

O desenho Pokémon contava a história de crianças e adolescentes que iam à escola e uma de suas atividades era encontrar e treinar monstros. Ao invés de ficarem guardados nos bolso, os bichinhos eram aprisionados em pokebolas, para que depois fossem jogados em batalhas mortais por meio das quais seria possível fazer o seu "pupilo" evoluir (TECNOVESTE, 2016). De fato, os pokemóns correspondem às centenas de criaturas, simbolizadas em animais, plantas, mitos e objetos. Em comum, reside o fato de que todas elas possuem poderes especiais relacionados a elementos da natureza e que, com o treinamento certo, podem apresentar uma evolução para formas cada vez mais poderosas (CARMO; GUSHIKEN; HIRATA, 2013).

Apesar de o nome Pokémon sugerir que os "monstros" ficariam "no bolso", é de se salientar a incrível vocação de tal game para a exploração dos mais diversos espaços. De acordo com Pereira (2016), o Pokémon GO seria um dos exemplos mais recentes de "jogos pervasivos" baseados na localização com um elevado grau de sucesso, já que contou com mais de 50 milhões de transferências na Google Store. Segundo o autor, um jogo pervasivo é definido por ter a capacidade de levar a experiência de jogo do mundo virtual para o real, permitindo ao jogador mover-se pelo jogo usando o seu dispositivo móvel e ligando a experiência de jogo à experiência do mundo real. Este sucesso seria legitimado pelo fato do jogo combinar a fórmula base do franchise, a captura de Pokémon, com o mundo real, tendo como recurso opcional a realidade aumentada e permitindo aos seus jogadores encontrar os ditos "monstros" enquanto caminham.

O Pokémon Go possibilitou assim criar uma camada do universo Pokémon sobre o mundo real, tomando como base a localização do jogador capturada pelos sensores Global Positioning System - GPS. Na prática, isso significa que os jogadores podem interagir com o mundo real proporcionando uma experiência imersiva particular nunca vista em um jogo produzido para larga escala (PIMENTA, 2016).

O trabalho a seguir é fruto de pesquisa realizada com alunos universitários jogadores de Pokémon GO. O lócus de pesquisa é a Escola de Artes, Ciências e Humanidades da Universidade de São Paulo. O problema foi delimitado tendo como encaminhamento a seguinte questão: considerando o Pokémon GO uma forma de lazer virtual, seria o meio universitário um ambiente de hospitalidade em termos de sociabilidade para os alunos que jogam tal game?

O objetivo foi o de verificar a relevância do Pokémon GO em termos de atividade de lazer e entretenimento para os alunos da Universidade de São Paulo e de que maneira tal ambiente universitário poderia tanto estimular tal prática como potencialmente ser melhorado para abrigar os usuários do referido jogo. Para tal, foi realizada uma revisão de literatura sobre o lazer, a virtualidade e a hospitalidade bem como apresentados os dados colhidos em campo com alunos universitários oriundos da Escola de Artes, Ciências e Humanidades, atualmente uma das maiores unidades da Universidade de São Paulo.

\section{Revisão de literatura}

Considerando o recente lançamento do Pokémon GO e ainda restrito a alguns lugares do mundo, era já de se esperar uma clara dificuldade em encontrar fontes acadêmicas que pudessem embasar a discussão sobre os valores associados a tal game. Contudo, verificam-se trabalhos já publicados, em especial na área de comunicação e medicina, que podem auxiliar no debate aqui proposto. 
Segundo Serino et al (2016), apesar dos potenciais benefícios da prática do Pokémon Go para as crianças e adolescentes em virtude dos inerentes aspectos de sociabilização pelo jogo em ambientes outdoor, o recente lançamento do game tem fomentado uma nova série de desafios para os pais e médicos pediatras pois podem colocar em risco a saúde e a segurança dos seus jogadores. Tais riscos estariam consubstanciados pela possibilidade de incidentes/acidentes, sequiestros, assaltos e demais elementos associados à violência urbana. Sugerem assim que os pais estejam atentos aos efeitos maléficos na prática de tal jogo, regulando a participação de seus filhos e mantendo vigilância para evitar potenciais circunstâncias perigosas.

Ainda no campo médico, de forma semelhante, McCartney (2016) alerta para os efeitos negativos do Pokémon Go. Apesar de reconhecer que o jogo é a nova "sensação" por inclusive proporcionar uma significativa ajuda no combate à obesidade, à depressão e até mesmo à Diabetes tipo 2 pela associação com a prática da atividade física, por outro lado traz uma série de efeitos maléficos por atrair criminalidade para os pontos conhecidos de coletas de Pokémons e incrementam as estatísticas de resgate nos serviços de emergência médica realizados de forma remota em cavernas e oceanos.

Os alertas para os perigos oriundos da prática do Pokémon Go motivaram até mesmo uma manifestação formal da National Society for the Prevention of Cruelty to Children do Reino Unido. Intitulada como "Pokémon Go: Our open letter to Nintendo UK", tal associação reclama à companhia gestora do game sobre o atentado aos direitos fundamentais da segurança das crianças por expô-las a constantes riscos como assaltos de aparelhos de celulares e até mesmo o incentivo para a freqüência de pontos não desejáveis para crianças, como sex shops. A associação relembra que o governo do Reino Unido tem atuado desde 2014 junto ao mercado de games para atentar à proteção das crianças e adolescentes e solicita assim à empresa que remodele o app para ampliar a segurança dos seus jogadores com constantes alertas sobre locais e situações perigosas (NSCPP, 2016).

O forte apego ao Pokémon Go acabou também se tornando um problema em termos de crimes virtuais. Diversos artigos na mídia eletrônica deram destaque ao surgimento de um "software espião" com uma versão visualmente semelhante ao game criada por hackers. Tal versão trouxe diversos problemas para o aparelho celular do jogador, criando indesejáveis situações como a leitura e o envio de mensagens, o ativamento/desativamento de redes sem fio e $3 \mathrm{G}$ bem como o acesso ao histórico de chamadas com a possibilidade de efetuar ligações sem o consentimento do proprietário do aparelho (SEGURANÇA DIGITAL, 2016).

Não obstante a este cenário, cresce vertiginosamente o apego não somente pelo Pokémon GO mas também pelas diversas formas de lazer no ambiente virtual. Segundo Schwartz e Moreira (2007), o chamado "entretenimento virtual" é uma das indústrias mais promissoras da atualidade, atraindo adeptos de diversos pontos no mundo e dos mais diferenciados níveis sociais, gênero, idade e formação. Como nos ressalta Trigo (2003, p.163), "A indústria do entretenimento é uma representação da trama delicada e intricada da vida. Encarar a vida como um brinquedo ou um jogo é parte integrante dessa indústria".

Pires e Antunes destacam que nos últimos anos tem se expandido de forma intensa as chamadas mídias digitais, constituídas por microcomputadores, softwares, hardwares, o telefone celular e a internet. Os autores destacam que "[...] as novas tecnologias de informação/comunicação estão presentes no cotidiano de um contingente cada vez maior de grupos populacionais diversificados, tornando-se um suporte tecnológico cujo acesso vem-se popularizando" (PIRES; ANTUNES, 2007, p.99). 
Defende-se aqui que o apego ao Pokémon GO se circunscreve neste cenário de desenvolvimento das tecnologias de informação e comunicação. Com um aparelho de celular e razoável acesso à internet, é possível experienciar uma realidade virtual significativa aliada à portabilidade do equipamento de jogo no deslocamento pelo espaço.

A Escola de Artes, Ciências e Humanidades da Universidade de São Paulo EACH/USP é considerada uma das maiores unidades desta instituição em termos de volume de alunos. Localizada na zona Leste da cidade de São Paulo e inaugurada em 2005, oferece atualmente 10 cursos de graduação e 11 de pós-graduação (mestrado/doutorado) reunindo um grupo de aproximadamente 5000 alunos distribuídos em três períodos: matutino, vespertino e noturno.

Além dos usuais espaços do setor universitário para possíveis práticas de lazer, como as quadras poli esportivas, salas para lutas e danças, espaço dos estudantes, entre outros, chama a atenção atualmente sobre como a unidade vem sendo utilizada para práticas das mais diversas em termos de entretenimento, como é o caso do Pokémon GO. Com base nos relatos adquiridos em campo e que serão analisados detidamente mais a frente, apresentamos aqui a Figura 1 que procura identificar os principais pontos de prática do jogo na EACH/USP:

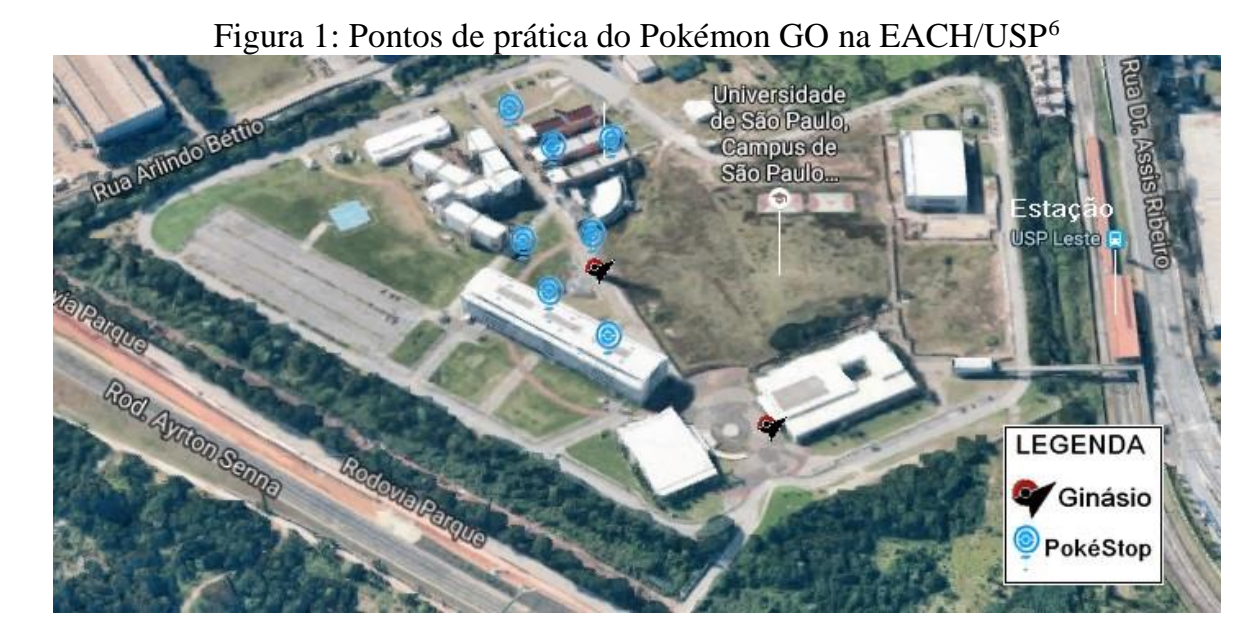

O que se vê na legenda da figura anterior, intitulados "Ginásio" e "PokéStop", faz parte de um glossário bem peculiar destes jogadores de Pokémon Go. A seguir, apresentamos um quadro com os principais termos coletados em campo bem como sua breve explicação:

\footnotetext{
${ }^{6}$ Dados obtidos em campo pelos praticantes do jogo. O mapa foi adaptado do Google Maps e os ícones da Niantic, empresa desenvolvedora do Pokémon GO (2016).
} 
Quadro 1: Principais termos utilizados no Pokémon $\mathrm{GO}^{7}$

\begin{tabular}{|c|l|}
\hline Candy & $\begin{array}{l}\text { Item obtido ao capturar um Pokémon. Indispensáveis para deixar seu Pokémon mais } \\
\text { forte e para evoluí-lo. }\end{array}$ \\
\hline Game Boy & Primeiro console de vídeo game portátil da Nintendo. \\
\hline Ginásios & $\begin{array}{l}\text { Locais onde os jogadores treinam os Pokémons, quando o ginásio é de uma equipe } \\
\text { adversária você pode desafiar os Pokémons que estão guardando o ginásio e tentar } \\
\text { tomar posse dele para a sua equipe/time. }\end{array}$ \\
\hline Pokébola & $\begin{array}{l}\text { Consiste num treinador Pokémon com alto nível de habilidade e que, por mérito, } \\
\text { recebe titulo de mestre (referência ao anime) } .\end{array}$ \\
\hline Pokédex & $\begin{array}{l}\text { Item utilizado para capturar e guardar Pokémons. Existe uma variedade de } \\
\text { pokébolas, apresentadas pelo nível de eficiência: Poké Ball, Great Ball, Ultra Ball } \\
\text { e Master Ball. }\end{array}$ \\
\hline Pokéstop & $\begin{array}{l}\text { Catálogo que mostra todos os Pokémons que você encontrou e capturou. } \\
\text { tugásticos ou em lugares de alta movimentação. Para utilizar um pokéstop basta clicar } \\
\text { neles, girar e esperar os itens aparecerem. }\end{array}$ \\
\hline Realidade aumentada & $\begin{array}{l}\text { Tecnologia utilizada em Pokémon GO que sobrepõe ao mundo real os elementos } \\
\text { digitais, no caso especifico os Pokémons. }\end{array}$ \\
\hline TCG & $\begin{array}{l}\text { Jogo de cartas colecionáveis, que atualmente possui uma versão digital disponível } \\
\text { gratuitamente. }\end{array}$ \\
\hline Trimes & $\begin{array}{l}\text { Ao chegar ao nível 5, o jogador deve escolher um time, sendo eles o Mystic, o } \\
\text { Instinct e o Valor. O time será escolhido em algum Ginásio. }\end{array}$ \\
\hline Treinador pokémon & Nomenclatura dada aos jogadores de Pokémon GO. \\
\hline Trading Card Game & \\
\hline &
\end{tabular}

Como será identificado a seguir, a EACH/USP vem se mostrando um local bastante propício para a prática do Pokémon Go. É possível visualizar, em distintos momentos do dia e da noite em que a unidade está em funcionamento, diversos jogadores com os seus celulares em mãos caminhando pelo espaço universitário. Tal espaço vai ganhando assim um significado especial para os seus jogadores ao se tornar um relevante ambiente não somente para os estudos acadêmicos mas também para o compartilhamento de atividades de lazer. Como nos aponta Baptista:

As sociedades urbanas, à medida que se desenvolvem e complexificam, vão perdendo o sentido de vida em comunidade, requerido por uma solidária convivência entre pessoas. É certo que o anonimato próprio da vida urbana oferece a vantagem de garantir uma certa privacidade, necessária também à afirmação de uma liberdade pessoal. Mas ao inviabilizar os tradicionais espaços de encontro, a vida urbana põe, por outro lado, em risco a emergência e a consolidação de laços sociais (BAPTISTA, 2002, p.162).

\footnotetext{
${ }^{7}$ Dados também obtidos em campo com os jogadores do Pokémon GO. As explicações são adaptadas da obra de Prandoni (2016).
} 
Ao acomodar os praticantes de Pokémon Go em seu ambiente, que se reconhecem e partilham de valores associados ao lazer virtual, a universidade pode, a nosso ver, se aproximar de um contexto atrelado à hospitalidade, ainda que seus gestores não tenham necessariamente preparado o campus para que tais práticas ali ocorressem. Como bem destaca Camargo:

\begin{abstract}
Definir como objeto de estudo da hospitalidade as diferentes formas e modelos de relações humanas e o resultado do ponto de vista do reforço ou do esgarçamento do vínculo humano serve também para mostrar que a hospitalidade diz respeito à relação entre seres humanos. Uma empresa não é hospitaleira ou inospitaleira: seus responsáveis, aqueles que atendem o público é que são! Uma cidade não é hospitaleira ou inospitaleira: os que (não) planejaram adequadamente o espaço urbano, aqueles com os quais nos relacionamos é que (não) o são (CAMARGO, 2015, p.49).
\end{abstract}

Apresentaremos a seguir o delineamento metodológico que foi traçado para a pesquisa bem como os dados colhidos em campo que irão fortalecer a proximidade entre o lazer, a virtualidade e a hospitalidade a partir da prática do Pokémon GO por estudantes universitários.

\title{
Percurso metodológico
}

O procedimento metodológico adotado foi o do tipo qualitativo, combinando os enfoques bibliográfico e de campo. Foi escolhida uma pesquisa qualitativa por melhor possibilitar a análise das representações dos sujeitos pesquisados acerca do fenômeno estudado, neste caso o lazer em suas relações com o ambiente virtual na Universidade de São Paulo, com destaque para o jogo do Pokémon GO. A pesquisa qualitativa, conforme nos ensina Minayo, Hartz e Buss (2000), trabalha com o universo de significados, motivos, aspirações, crenças, valores e atitudes, correspondendo a um espaço mais profundo das relações, dos processos e dos fenômenos que não podem ser reduzidos à operacionalização de variáveis.

A pesquisa também se caracterizou como de caráter exploratório, que segundo Gil (2011, p. 27), apresenta como objetivo “[...] proporcionar visão geral, de tipo aproximativo, acerca de determinado fato", e, portanto "[...] é realizado especialmente quando o tema escolhido é pouco explorado e torna-se difícil sobre ele formular hipóteses precisas e operacionalizáveis".

O enfoque bibliográfico foi realizado em livros, dissertações e recentes artigos científicos publicados sobre a temática do lazer virtual, com busca centrada na recente produção sobre o Pokémon GO.

Já o de campo compreendeu um questionário aplicado com jogadores de Pokémon GO escolhidos aleatoriamente e compreendidos dentre um grupo de alunos da Escola de Artes, Ciências e Humanidades - EACH/USP. Tal questionário foi aplicado utilizando-se do ambiente virtual a partir do envio de e-mail e pelas redes sociais. Foram selecionados 60 jogadores, todos necessariamente alunos da referida unidade da USP e oriundos de distintos cursos de graduação e pós-graduação. As questões norteadoras da pesquisa buscaram identificar as representações e os significados dos temas relacionados ao entretenimento, à virtualidade, ao ambiente universitário e sua potencial hospitalidade para a prática de tal jogo, aprofundando o significado do lazer neste contexto. 


\section{Apresentação e análise dos dados}

Uma questão inicial conferida aos sujeitos de pesquisa era sobre a idade, com o intento de conhecer a variância geracional dos respondentes. Neste âmbito, é possível observar que há uma variação de idade para os respondentes que vai de 18 anos até 58 anos. Fato que se mostrou uma surpresa na pesquisa já que se estimava uma maior parte de respondentes com idade inferior a 25 anos devido ao maior contato desta faixa etária com o Pokémon na infância.

Assim, é possível aprender do Gráfico 1 que há uma heterogeneidade geracional entre os respondentes, ainda que a maioria esteja registrada abaixo da idade de 23 anos:

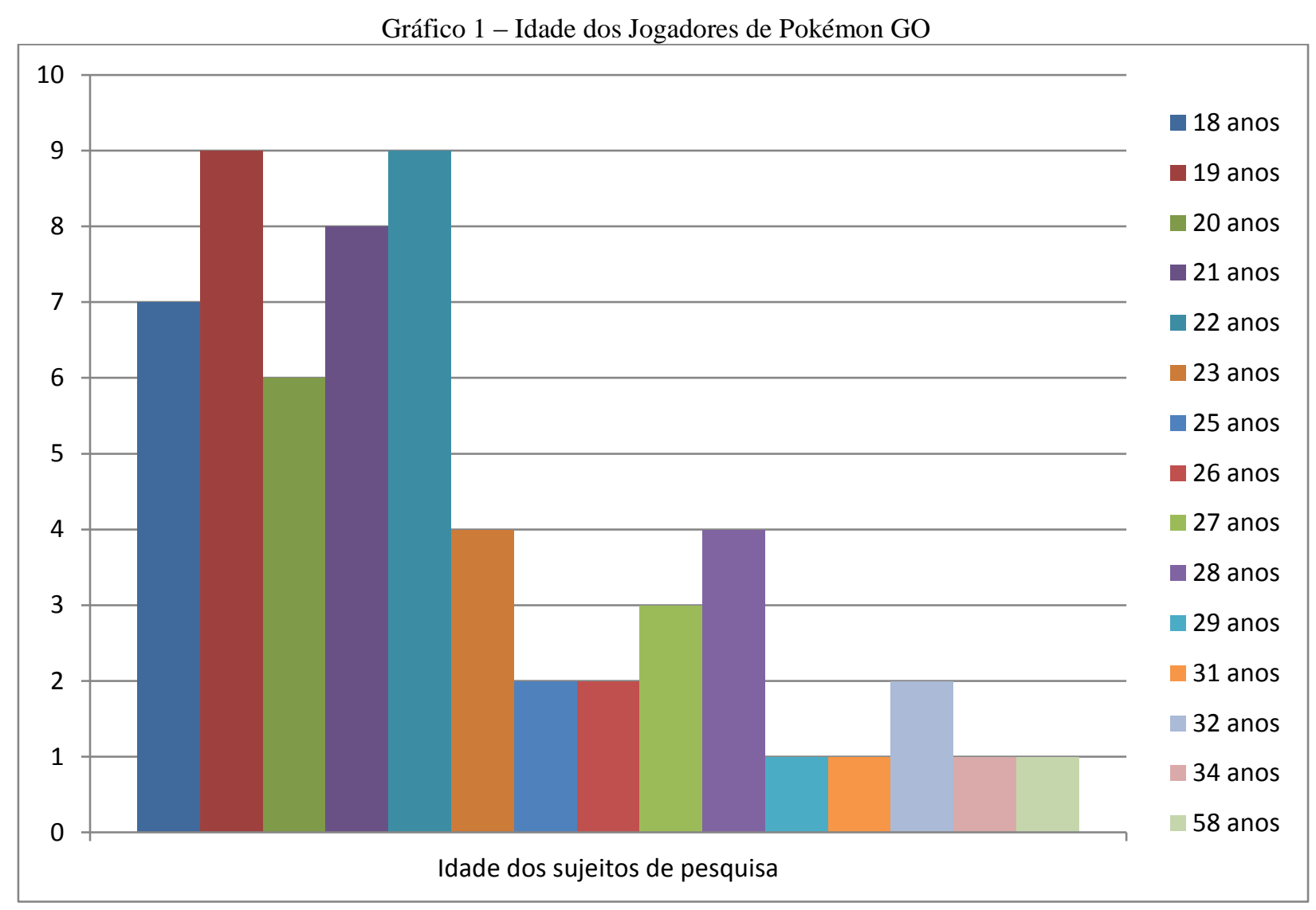

Fonte: Autores, 2016

Buscou-se também identificar em campo a correlação do apego ao jogo no celular com o fato de se ter assistido regularmente no passado o anime Pokémon na televisão. O gráfico 2 ressalta que mais de $75 \%$ das pessoas questionadas assistiam diariamente ou pelo menos algumas vezes na semana ao anime, sugerindo uma certa identificação com o produto cultural Pokémon. Pode-se, a partir daí, inferir que os respondentes, de uma maneira geral, assistiam o desenho na televisão com um maior interesse em relação a outros produtos de Pokémon. 
Gráfico 2 - Apego ao anime Pokémon

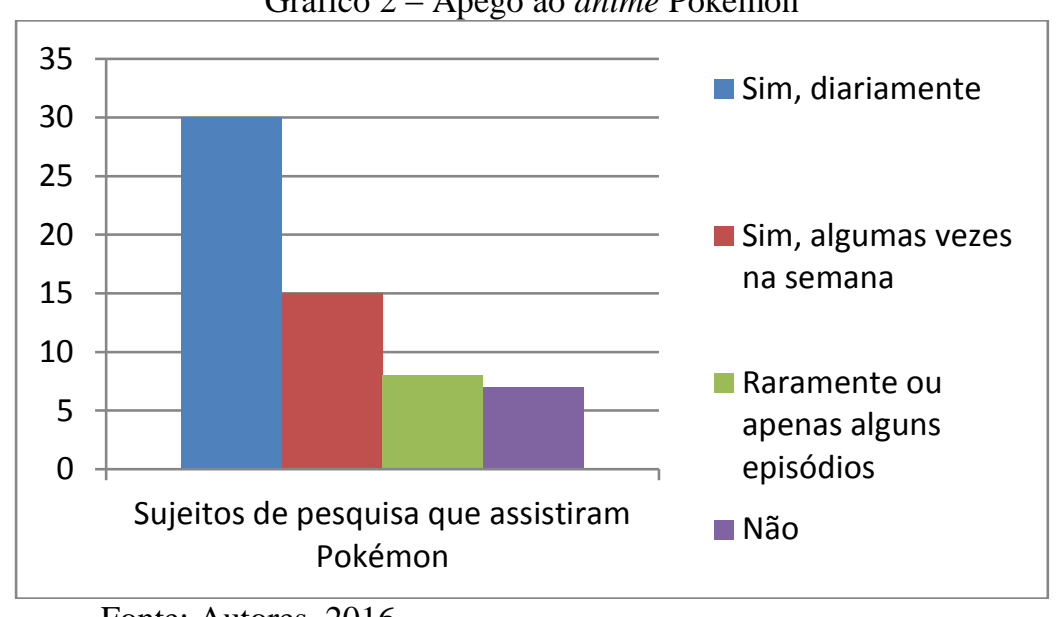

Fonte: Autores, 2016

Um dos objetivos máximos em se jogar o Pokémon Go é conquistar o status de "Mestre Pokémon", como destacado anteriormente. Foi questionado ao grupo de entrevistados sobre o possível desejo em chegar neste estágio. No gráfico 3, verifica-se que mais da metade possui tal objetivo, possivelmente alimentado pela aderência ao anime Pokémon como demonstrado no gráfico anterior.

Gráfico 3 - Desejo de se tornar um Mestre Pokémon

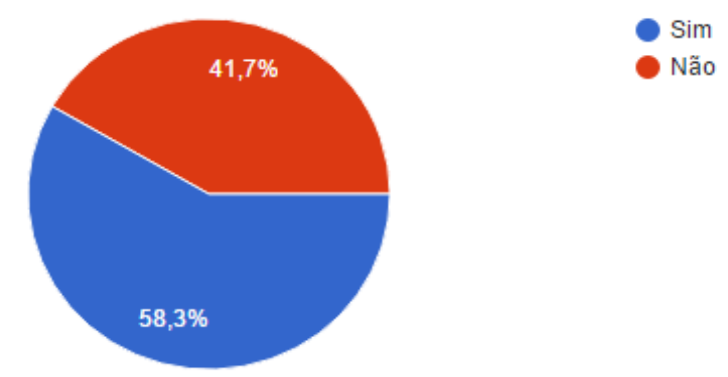

Fonte: Autores, 2016

Já o Gráfico 4 traz uma questão para investigar se os jogadores de Pokémon GO no celular teriam tido algum contato prévio com tal jogo em outras plataformas, como no game boy. Cerca de $87 \%$ dos sujeitos responderam positivamente, sugerindo que não somente o anime mas também o jogo na plataforma game boy teriam influenciado na motivação em se jogar atualmente Pokémon GO no celular. 
Gráfico 4 - Experiência prévia do jogo Pokémon GO em outras plataformas
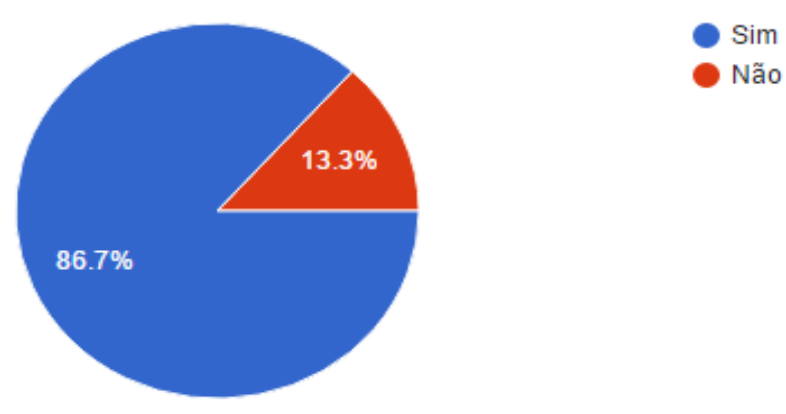

Fonte: Autores, 2016

Quando questionados sobre os possíveis motivos que os levaram a jogar Pokémon GO no ambiente universitário (aqui no caso, na EACH/USP), diversas razões foram apontadas. Majoritariamente, algo em torno de $60 \%$ apontou a motivação de jogar devido às lembranças de infância. Também é expressivo aqueles que destacam que jogam Pokémon GO pela popularidade/sucesso do jogo alcançado desde seu lançamento no Brasil, algo em torno de $48,3 \%$.

Ainda no Gráfico 5, vale ressaltar que cerca de $45 \%$ dos respondentes declararam que consideram o ambiente universitário seguro, motivação para jogar tal game na EACH/USP, além do fato do campus da USP Leste apresentar elevada concentração de PokeStops e Ginásios que a nosso ver facilitam a multiplicação de adeptos ao jogo. Observa-se ainda que $30 \%$ dos jogadores se disseram influenciados a realizar o download do jogo por amigos da universidade, em que o aspecto da sociabilização se torna uma tônica importante em tal ambiente. $\mathrm{O}$ item "Outros" não recebeu qualquer resposta qualificada. Ressalta-se que os respondentes tinham a possibilidade de escolher quantas alternativas quisessem em tal questão.

Gráfico 5 - Motivações para se jogar Pokémon GO no ambiente universitário

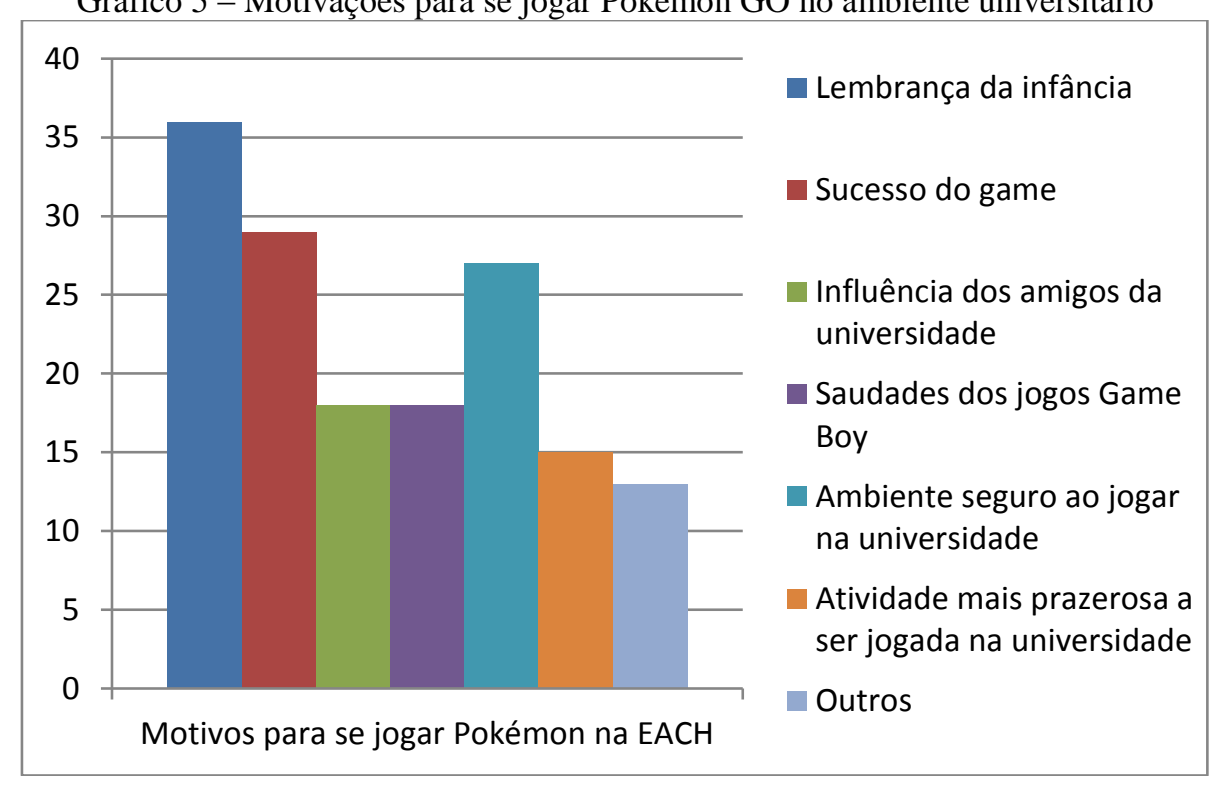

Fonte: Autores, 2016 
Em complemento às motivações de se jogar Pokemón GO, foi questionado quais seriam os aspectos especificamente no jogo que os levariam a experienciar tal game em seus celulares no ambiente universitário. Pode-se observar no Gráfico 6 que a possibilidade de "capturar pokémons" foi o índice mais lembrado, algo em torno de 70\% das respostas. Chama também atenção a utilização do game para passar o tempo livre na universidade, fato que atingiu $50 \%$ das respostas. Também foram destacadas a possibilidade de "conquistar ginásios", a realidade aumentada proporcionada pelo jogo e a possibilidade de fazer amigos com interesses comuns, este último bastante calcado no aspecto da sociabilização potencial de tal jogo. Finalmente, na alternativa "outros", foi lembrada pelos respondentes a segurança proporcionada em se jogar dentro do campus.

Gráfico 6 - Aspectos relevantes para se jogar Pokémon GO no ambiente universitário

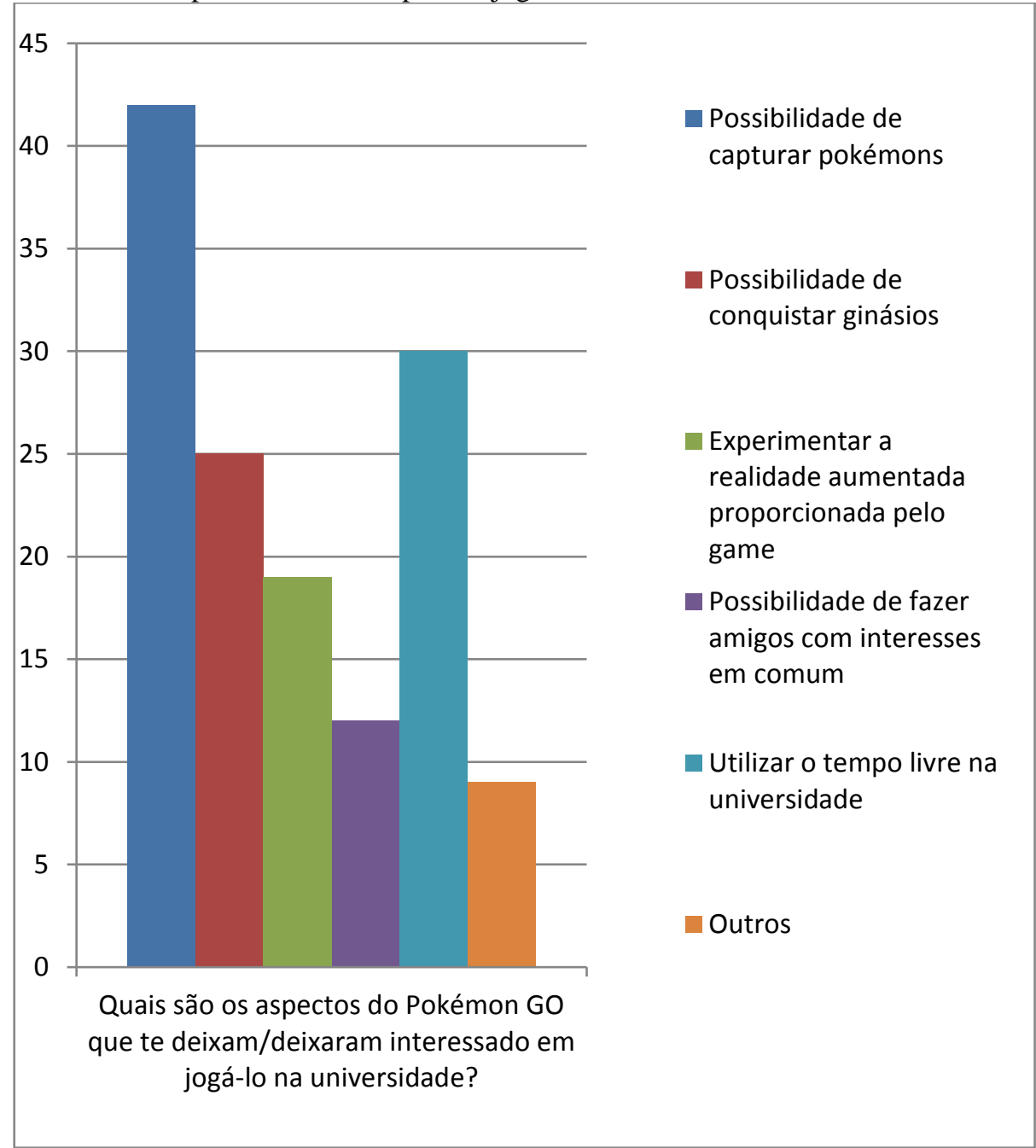

Fonte: Autores, 2016 
No que concerne à correlação entre o Pokémon GO e o lazer, no Gráfico 7 verifica-se que $95 \%$ das pessoas consideram tal jogo como significativa forma de atividade em tal esfera social, corroborando nossa assertiva inicial que tal jogo teria importância singular no tempo livre dos jogadores e em especial no seu gosto por atividades relacionadas ao ambiente virtual.

Gráfico 7 - O Pokémon GO e sua representação como atividade de lazer

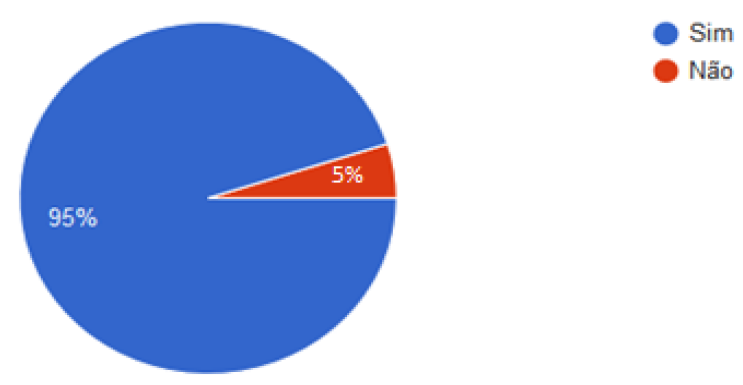

Fonte: Autores, 2016

Entende-se que o Gráfico 7 apresenta um importante complemento aos dados veiculados no Gráfico 6, já que se verifica a potencialidade do Pokémon GO como atividade a ser praticada no tempo livre das pessoas bem como o favorável ambiente encontrado na universidade em períodos de intervalo das aulas. Em suma, parte considerável dos entrevistados aponta que gosta de jogar Pokémon GO na universidade e geralmente o fazem como atividade de lazer para além das obrigações escolares, conferindo um interessante aspecto de hospitalidade em tal ambiente.

O Gráfico 8 corrobora o aspecto lúdico atrelado ao divertimento/entretenimento em tal jogo, sendo "Diversão", "Utilização no tempo livre", "Entretenimento" como alternativas bem lembradas nas respostas. 
Gráfico 8 - Motivos para se considerar o Pokémon GO uma atividade de lazer

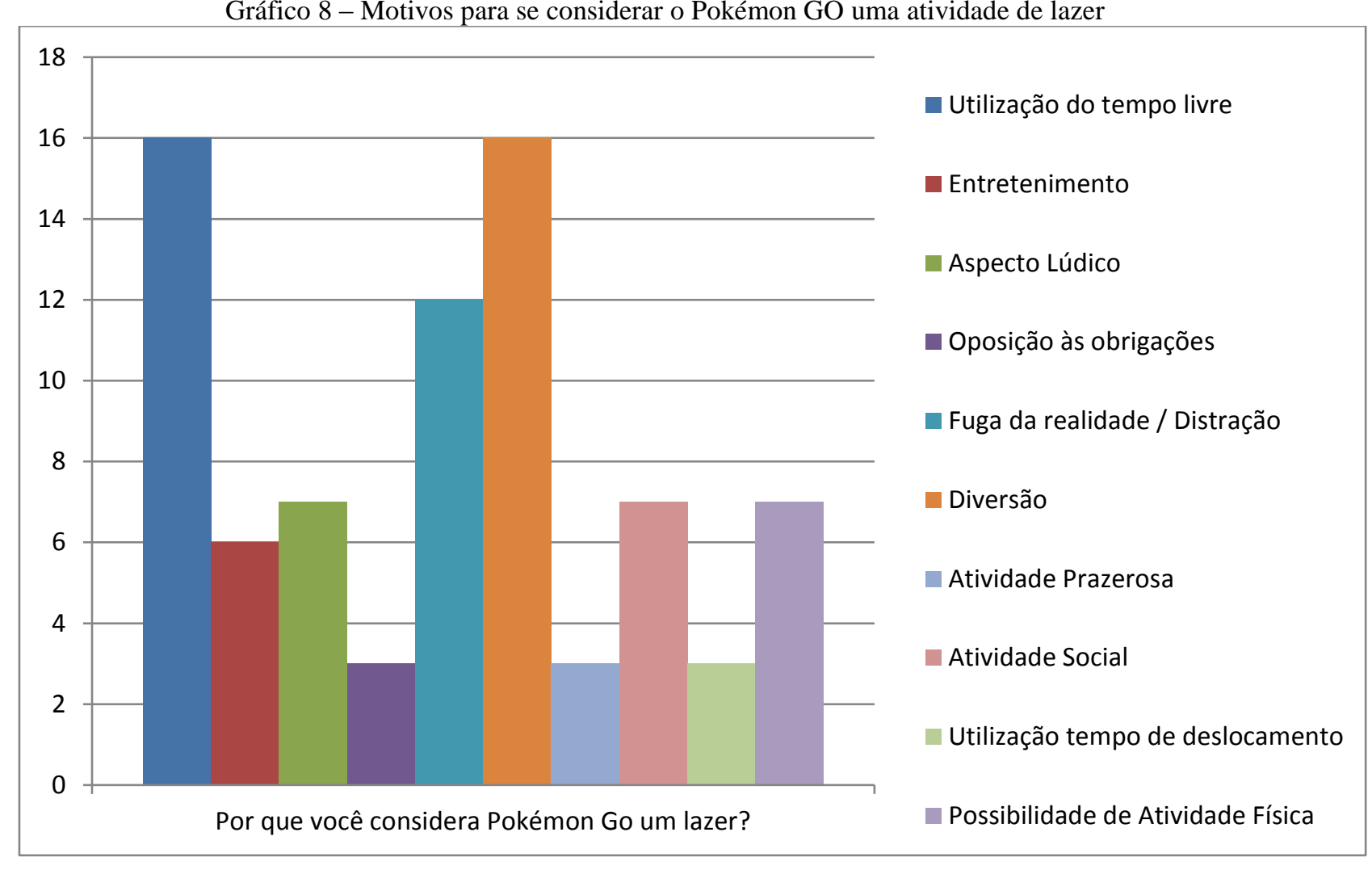

Fonte: Autores, 2016

Verificam-se ainda aqueles que consideram o Pokémon GO uma "fuga da realidade" ou ainda a possibilidade de "oposição" às obrigações cotidianas, o que a nosso ver confere uma vertente um tanto funcionalista a tal prática. Para além dos dados apresentados no gráfico, nos captou a atenção uma das respostas de um jogador que não considerava o Pokémon GO uma atividade de lazer. Para ele, o Pokémon GO não poderia ser simplesmente uma atividade de lazer, e sim "um estilo de vida".

Procurando uma correlação entre lazer e virtualidade, os jogadores foram questionados sobre a representatividade de suas atividades de lazer serem praticadas em ambientes virtuais, como redes sociais, jogos online, entre outros. Os resultados no Gráfico 9 apontam que 58,3\% dos sujeitos afirmam realizar "a maioria" de suas atividades de lazer em plataformas virtuais, o que ganha ainda maior expressividade se somarmos com aqueles que dizem ser "todas" as atividades de lazer no meio virtual $(3,3 \%)$. 
Gráfico 9 - Atividades de lazer no ambiente virtual

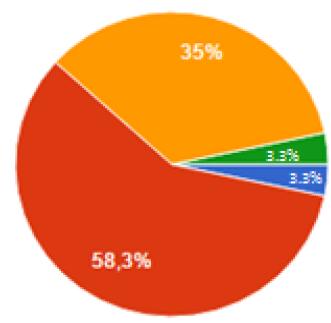

Todas as atividades de lazer são
praticadas em ambiente virtual
A maioria das minhas atividades de
lazer são praticadas em ambiente
virtual
Poucas das minhas atividades de
lazer são praticadas em ambiente
virtual
Nenhuma das atividades de lazer
såo praticadas em ambiente virtual

Fonte: Autores, 2016

Finalmente, a última questão, apresentada no Gráfico 10, procurava explorar o entendimento sobre como o ambiente da EACH/USP poderia acolher melhor os jogadores de Pokémon GO e se tornar um ambiente mais hospitaleiro para aqueles que são adeptos a tal prática. Com elevada incidência aparece o desejo de uma melhoria no sinal de internet no campus, o que a nosso ver se justifica pela expressiva carga de internet em dados móveis que é necessária para possuir uma boa experiência no aparelho celular com as dinâmicas do jogo.

Gráfico 10 - Melhorias na universidade para a prática do Pokémon GO

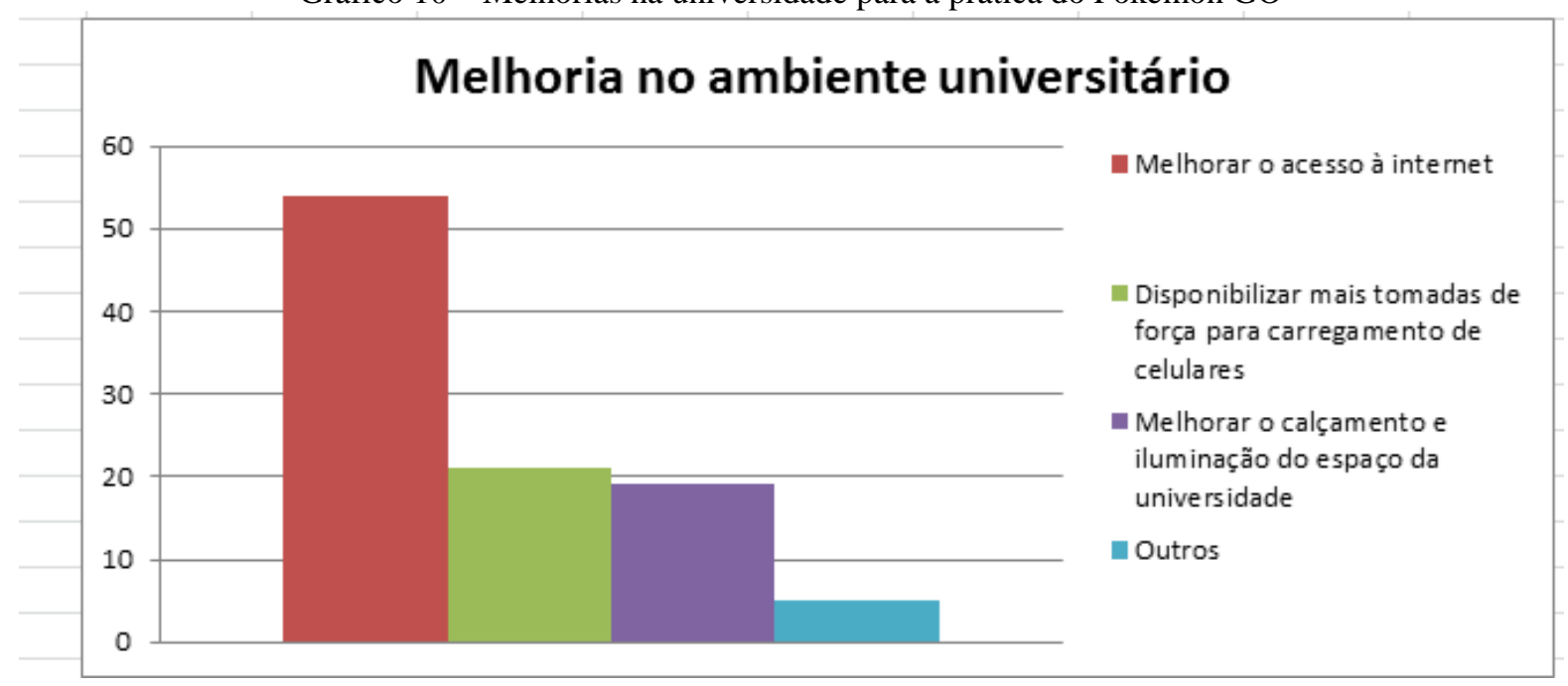

Fonte: Autores, 2016

Em termos infraestruturais, também mereceu destaque no Gráfico 10 o desejo nos jogadores de se ter mais tomadas de carga para carregar a bateria dos celulares. Neste quesito, acredita-se que tal apelo deve-se ao fato de que a prática de Pokémon GO, principalmente no modo interativo de realidade aumentada, acaba por exigir muito das baterias do aparelho celular implicando contínuas recargas.

Para efeitos da discussão sobre lazer, virtualidade e hospitalidade, entende-se que merece ainda consideração no gráfico a alternativa em que se observa a solicitação aos gestores da universidade para a melhoria da experiência com o Pokémon GO naquele ambiente, em providências que incluiriam a otimização do calçamento das vias internas do campus e uma 
melhor drenagem das poças d'água formadas em dias de chuva. A alternativa "outros" não apresentou respostas que pudessem colaborar para a discussão realizada neste texto.

\title{
Considerações finais
}

Iniciada a pesquisa, eram esperados diversos fatores que justificassem não somente o visível sucesso do Pokémon GO, mas também sua importância no tempo livre dos jovens pesquisados. Os dados coletados não apenas corroboraram tais elementos como também demonstraram relevantes pontos que elencamos a seguir.

Inicialmente, a constatação de que nem todos os jogadores atuais de Pokémon GO tiveram expressivo contato com outros produtos anteriores da franquia Pokémon, como o anime televisivo e o jogo da plataforma portátil Game Boy. Assim, o Pokémon GO surgiu como interessante oportunidade de entretenimento virtual para um novo grupo de jogadores sem que se correlacionasse necessariamente com uma possível "nostalgia Pokémon".

Neste âmbito, nos parece um tanto significativa a influência dos colegas de universidade para o apego ao tal jogo atualmente, sendo que elementos como sociabilidade com os amigos num ambiente hospitaleiro e utilização do tempo livre com atividades de entretenimento sugerem ser fundamentais para explicar o sucesso de Pokémon GO dentro da EACH-USP. Os gestores de tal unidade da USP deveriam assim, a nosso ver, estar atentos às possibilidades de incrementar a experiência dos jogadores, num ambiente acolhedor e devidamente planejado próximo ao que nos ensina Baptista:

\begin{abstract}
A hospitalidade permite celebrar uma distância e, ao mesmo tempo, uma proximidade, experiência imprescindível no processo de aprendizagem humana. Portanto, é urgente transformar os espaços urbanos em lugares de hospitalidade. Não uma hospitalidade convencional ou artificial, reduzida a um ritual de comércio e falsa cortesia, mas uma hospitalidade ancorada no carinho e na sensibilidade que só podem ser dados por outra pessoa (BAPTISTA, 2002, p.162)
\end{abstract}

Pode-se ainda observar as variadas formas de lazer que Pokémon GO possibilita para seus jogadores no ambiente universitário. Aliás, tal game no celular se soma as diversas outras atividades realizadas pela maioria dos respondentes da pesquisa no chamado "ambiente virtual", tais como o uso de redes sociais, de jogos online em computadores e tablets, entre outros. Estas virtualidades, em grande parte desenvolvidas no tempo livre dos estudantes, permitem que os adeptos de tais atividades se encontrem e compartilhem os seus gostos, independente do curso acadêmico de origem ou de vínculos de amizade anteriormente traçados. Como bem enfatiza Camargo:

\footnotetext{
A hospitalidade, mais do que um fato observável, é uma virtude que se espera quando nos defrontamos com o estranho (e todo estranho é também um estrangeiro), alguém que ainda não é, mas deve ser reconhecido como o outro. Tudo se passa como se o sentido mais importante da noção seja perguntar-se se esse encontro resultou em estreitamento ou esgarçamento do vínculo social de início buscado (CAMARGO, 2015, p.44).
}

É destaque que o jogo do Pokémon GO na plataforma do aparelho celular se mostra bastante recente no mundo todo e, em particular, no Brasil. Tal ponto coincide com a precária produção acadêmica até o momento sobre o tema, em que se considerem seus efeitos benéficos e maléficos para os jogadores. O fato é que o jogo simboliza para seus praticantes uma 
oportunidade de se entreter, de forma bem correlata a que Trigo nos simboliza: "O entretenimento sempre garantirá uma migalha virtual do sonho ou uma satisfação simulada do desejo, ou então os momentos de ócio tornarão menos pesado o fardo monótono e algumas vezes dolorido do cotidiano" (TRIGO, 2003, p.153).

O texto aqui apresentado é apenas um recorte de um lócus de pesquisa universitário que não necessariamente permite generalizações. Contudo, os dados oriundos da pesquisa implicam na importância de se estudar e compreender esse recente sucesso mundial em termos de impacto nas atividades de lazer de seus jogadores, além de analisar fatores que envolvem os universitários com o jogo e como a EACH/USP tornou-se, involuntariamente, hospedeira de alunos praticantes de Pokémon GO. Este cenário sugere que futuras pesquisas temáticas possam abarcar elementos que permitam uma análise mais profunda a respeito dos impactos deste game, enquanto uma atividade de entretenimento correlata ao lazer virtual e significativa no cotidiano de seus jogadores.

\section{Referências}

BAPTISTA, I. Lugares de hospitalidade. In: DIAS, C.M.de M. (Org). Hospitalidade: reflexões e perspectivas. São Paulo: Manole, 2002. p.157-164.

CAMARGO, L. O. de L. Os interstícios da hospitalidade. Revista Hospitalidade, São Paulo, v. XII, n. especial, p. 42-69, mai. 2015.

CARMO, J. P. de O.; GUSHIKEN, Y.; HIRATA, T. Os preceitos imagéticos de Pokémon como difusores da cultura japonesa. INTERCOM Sociedade Brasileira de Estudos Interdisciplinares da Comunicação, XV Congresso de Ciências da Comunicação na Região Centro-Oeste, Rio Verde - GO, 2013. p.1-14.

GIL, A. C. Métodos e técnicas de pesquisa social. 6 ed. São Paulo: Atlas, 2011.

MCCARTNEY, M. Game on for Pokémon Go. British Medical Journal, London, UK, v. 354: i4306, 2016. DOI: http://dx.doi.org/10.1136/bmj.i4306

MINAYO, M. C.; HARTZ, Z. M. A.; BUSS, P. M. Qualidade de vida e saúde: um debate necessário. Ciência e Saúde Coletiva, Rio de Janeiro, v. 7, n.1, p. 7-18, 2000.

NSCPP. National Society for the Prevention of Cruelty to Children. Pokémon Go: our open letter to Nintendo UK. 2016. Disponível em: https://www.nspcc.org.uk/fighting-for-childhood/newsopinion/pokemon-go2. Acesso em: 15.09.2016.

PEREIRA, D. B. Jogo baseado na localização para a otimização da experiência turística. Dissertação (Mestrado Integrado em Engenharia Informática e Computação da Faculdade de Engenharia). Porto (Portugal), Universidade do Porto, 2016.

PIMENTA, R. D. da H. Pokémon Go: imersão, publicidade e ludicidade em um novo modelo de compra e inserção de mídia. INTERCOM Sociedade Brasileira de Estudos Interdisciplinares da 
Comunicação, XXXIX Congresso Brasileiro de Ciências da Comunicação, São Paulo - SP, 2016. p.1-15.

PIRES, G. de L.; ANTUNES, S.E. Revisitando os interesses intelectuais do lazer mediante as inovações tecnológicas de informação/comunicação. In: MARCELLINO, N.C. Lazer e cultura. Campinas: Alínea, 2007. p. 89-117.

PRANDONI, C. Pokémon GO de A a Z. São Paulo: Panda Books, 2016.

SCHWARTZ, G.M.; MOREIRA, J.C.C. O ambiente virtual e o lazer. In: MARCELLINO, N.C. Lazer e cultura. Campinas: Alínea, 2007. p.149-170.

SEGURANÇA DIGITAL. Celular sem vírus. Disponível em: http://www.uol/noticias/conteudopublicitario/uol-seguranca-digital-proteja-seu-celular-de-virus.htm\#mas-como-eu-pego-o-virus. Acesso em 01.10.2016.

SERINO, M.; CORDREY, K.; MCLAUGHLIN, L.; MILANAIK, R.L. Pokémon Go and augmented virtual reality games: a cautionary commentary for parents and pediatricians. Current opinions in Pediatrics, Wolters Kluwer Health, USA, October 2016, v.28, issue 5, p.673-677.

TECNOVESTE. Por que meu filho gosta tanto do Pokémon GO? Correio Brasiliense. Disponível em: $\quad$ http://blogs.correiobraziliense.com.br/tecnoveste/porque-meu-filho-gosta-tanto-dopokemon-go. Acesso em 07.08.2016.

TRIGO, L. G. G. Entretenimento: uma crítica aberta. São Paulo: SENAC, 2003.

Recebido em: 28/10/2016

Reavaliado em: 02/11/2016

Aprovado em 11/11/2016 